\title{
Cardiac remodelling: General aspects and mechanisms
}

\author{
Henrique Budib Dorsa Pontes MS1, Jose Carlos Dorsa Vieira Pontes PhD², Euler de Azevedo Neto MS¹, \\ Alexandre Henrique Zangari $\mathrm{MD}^{3}$, Joao Victor Cunha Miranda MS ${ }^{1}$, Otoni Moreira Gomes $\mathrm{PhD}^{4}$
}

\begin{abstract}
HB Dorsa Pontes, JCD Viera Pontes, E de Azevedo Neto, AH Zangari, JV Cunha Miranda, O Moreira Gomes. Cardiac remodelling: General aspects and mechanisms. Curr Res Cardiol 2016;3(3):79-82.
\end{abstract}

The progression of heart failure is related to cardiac remodelling, which represents the sequence of events at the molecular, cellular and interstitial levels, leading to changes in the size, mass, geometry and function of the heart. Cardiac remodelling involves both adaptive and maladaptive phases of development. At the initial stage, it represents an adaptive response to maintain cardiac output, whereas in the late stage, it results in the occurrence of heart failure. Oxidative stress appears to be the main factor that induces transition of cardiac hypertrophy to heart failure as a consequence of alterations in signal transduction, dysfunction of the sarcolemma and sarcoplasmic reticulum, impairment of calcium handling, increases in cardiac fibrosis and progressive loss of cardiomyocytes. Elements that play a fundamental role at the initial stages of cardiac remodelling and are associated with cardiac hypertrophy include neurohormonal activation, represented by the elevation of angiotensin II and norepinephrine levels. On the other hand, prolonged neurohormonal activation, as well as inflammatory signalling due to increased levels of tumour necrosis factor- $\alpha$ and transforming growth factor- $\beta$, may be involved in the late stages of cardiac remodelling associated with heart failure. In its initial stages, cardiac remodelling appears to serve as an adaptive mechanism, whereas in its late stages this process is associated with molecular and cellular defects leading to the development of heart failure.

Key Words: Cardiac remodelling; Cardiac hypertrophy; Heart failure; Neurohormonal activation; Oxidative stress; TNF- $\alpha$; TGF- $\beta$

$\mathrm{H}$ eart failure (HF) is a worldwide health problem that affects approximately 26 million individuals (1). It is known that heart disease progresses to HF, and there is a link between cardiac remodelling and the development of HF. Cardiac remodelling is defined as a group of molecular, cellular and interstitial changes that manifest clinically as alterations in the size, mass, geometry and function of the heart after a stressful stimulus (2). This process is triggered by ischemia (myocardial infarction) (3,4), inflammation (myocarditis) (2), hemodynamic overload (workload by volume or pressure) (5) and neurohormonal activation $(6,7)$. Cardiac remodelling is considered to be not only an adaptive event but also a maladaptive phenomenon. In the acute phase of a myocardial stress, cardiac remodelling acts as an adaptive response that enables the heart to maintain cardiac output; however, after the prolonged stressful stimulus, this continuous process leads to progressive decompensation (8). As a result of this phenomenon, the heart develops cellular changes such as myocyte hypertrophy (2), necrosis (9), apoptosis (10-12), fibroblast proliferation (13), increased fibrillar collagen (14) and fibrosis (15). At the macroscopic level, it manifests as alterations in geometry of the heart (the chambers turn from an elliptical shape to a spherical shape), which is associated with progressive left ventricular dysfunction (2). Furthermore, this process involves abnormalities in energy metabolism, altered expression or function of contractile proteins, abnormalities in the events related to excitation-contraction coupling and changes in the extracellular matrix (ECM) (16). The present article aims to describe the pathophysiology of cardiac remodelling during the development of HF.

\section{OXIDATIVE STRESS AS A MAJOR EVENT IN CARDIAC REMODELLING}

Oxidative stress is defined as an excessive production of reactive oxygen species (ROS) juxtaposed with the antioxidant defense system. Many experimental and clinical studies have demonstrated an increased production of ROS in the failing heart $(17,18)$. ROS have four main sources: interaction of leukocytes with cytokines; abnormalities in mitochondrial respiratory chain; increased $\mathrm{NAD}(\mathrm{P}) \mathrm{H}$ oxidase reactivity; and increased xanthine oxidase function (19). During stressful events, the arachidonic acid cycle releases proinflammatory cytokines that interact with chemotactic leukocytes (neutrophils and macrophages) and release ROS in the tissue, leading to oxidative stress (20). It may be noted that oxidative stress has been shown to induce myocardial hypertrophy, cellular dysfunction, ECM remodelling, continuous inflammation and progressive myocyte loss by apoptosis (19).

Under normal conditions, a small amount of ROS are produced in the mitochondrial respiratory chain; this small quantity of $\mathrm{O}_{2}{ }^{-}$is detoxified by the antioxidant system. However, in HF, mitochondria release $\mathrm{O}_{2}^{-}$in significant quantities in the presence of NADH (21). Particularly in conditions in which oxygen availability is decreased, mitochondrial production of ROS is enhanced (22). During the tensin II and endothelin-1, are elevated in additon to tumour growth factor- $\alpha$, which increase NAD(P)H oxidase activity (23-25) and lead to ROS production (26). Xanthine oxidase enzyme expression and function are also elevated in HF, representing an additional source of ROS. Experimental studies have demonstrated the benefits of treatment with allopurinol, a xanthine oxidase inhibitor, in some animal models of HF (27-29).

\section{ROS AND CARDIAC HYPERTROPHY SIGNALLING}

'Redox signalling' is the term that defines ROS modulation of the activity of several subcellular pathways that can induce specific regulation in myocyte phenotype (30). ROS and neurohormonal stimulation can activate several protein kinases and transcription factors and, depending on the stimuli, can lead to different patterns of cardiac hypertrophy. Some subcellular pathways have already been described (30-32). Low levels of $\mathrm{H}_{2} \mathrm{O}_{2}$ are associated with an increase in the activity of mitogen-activated protein kinases (MAPK). MAPK cascades are complex multiple levels of kinases that include a phosphorylation-based amplification network normally activated by a membrane $G$ protein. MAPK cascades are classified into three major categories: development of HF, the levels of different hormones, such as angio-

${ }^{1}$ UNIDERP, University for the Development of the Pantanal Region; ${ }^{2}$ UFMS, Federal University of Mato Grosso do Sul, ${ }^{3}$ Cardiovascular Service;

${ }^{4}$ UFMG, Federal University of Minas Gerais, Cardiomed, Campo Grande, Mato Grosso do Sul, Brazil

Correspondence and reprints: Dr Henrique Budib Dorsa Pontes, University for the Development of the Pantanal Region, Mato Grosso do Sul, Brazil, 79002-121. E-mail henriquedorsa01@gmail.com 
p38 kinases; c-Jun N-terminal kinases; and extracellular regulated kinases (ERK) (31). Experimental studies have shown that transgenic mice overexpressing MEK-1 and ERK $1 / 2$ activation developed a concentric hypertrophy pattern, showing increased myocytes width (sarcomeres assembled in parallels) similar to the pattern of hypertrophy due to pressure overload, but without fibrosis (33). Other studies involving mice overexpressing activated mutant ERK5, related to the MEK5-ERK5 category of MAPK, have reported eccentric hypertrophy, exhibiting ventricular dilation and internal radius increasing (sarcomeres assembled in series), similar to the pattern of volume overload-induced hypertrophy, but again with no sign of fibrosis (34).

There are signal transduction pathways that are associated with the development of pathological fibrosis. The calcium/calmodulin activated protein phosphatase (calcineurin) pathway, which is activated during a sustained period of intracellular calcium elevation, facilitates attachment to the nuclear factor of activated T (NAFT) cells. Mice overexpressing an activated mutant calcineurin showed an increase in heart size, geometrical disorganization and extensive collagen deposition (35). Another kinase pathway involves $\mathrm{Ca}^{2+} /$ calmodulindependent kinase II (CaMKII), reflected by its expression and activity are enhanced in HF (36). Rats overexpressing CaMKII showed chamber dilation, myocyte enlargement and high levels of fibrosis (37). It is noted that an important change in the phenotype of the hypertrophied heart is the transition of the expression of myosin heavy chain $(\mathrm{MHC})$ gene expression. Under physiological conditions, $\alpha-\mathrm{MHC}$, which promotes faster shortening velocity of cardiac myofibres due to high ATPase activity, is predominant $(38,42)$. On the other hand, in $\mathrm{HF}$, there is a downregulation of $\alpha-\mathrm{MHC}$ and upregulation of $\beta-\mathrm{MHC}$, which is expressed in fetal genes, with less ATPase activity $(39,40,41,42)$. It has been shown that there is a correlation between the expression of $\beta$-MHC and the degree of cardiac hypertrophy (43). Thus, cardiac remodelling is invariably associated with a switch of myosin isozymes.

\section{OXIDATIVE STRESS AND NEUROHORMONAL ACTIVATION CAUSE CA ${ }^{2+}$ TRANSPORT DYSFUNCTION}

The two major structures that modulate the intracellular concentration of $\mathrm{Ca}^{2+}$, the sarcolemma (SL) and the sarcoplasmic reticulum (SR), also exhibit alterations in cardiac remodelling (44). In physiological conditions, the excitation-contraction process is activated after a small quantity of $\mathrm{Ca}^{2+}$ influx through $\mathrm{SL}$, which in turn stimulates a release of $\mathrm{Ca}^{2+}$ from the SR. In the relaxation phase, it is estimated that approximately $80 \%$ of the free cytoplasmic $\mathrm{Ca}^{2+}$ is accumulated in the SR (45). In cardiac remodelling, modifications in the expression of the saarcolemmal $\mathrm{Na}^{+} \mathrm{Ca}^{2+}$ exchanger (which uses the influx of $\mathrm{Na}^{+}$to remove the intracellular $\mathrm{Ca}^{2+}$ ) and the SR $\mathrm{Ca}^{2+}$-ATPase (SERCA) (which is responsible for $\mathrm{Ca}^{2+}$ sequestration during diastolic phase) have been reported (46). In this condition, messenger RNA and proteins levels of SERCA are reduced, whereas that of the $\mathrm{Na}^{+} \mathrm{Ca}^{2+}$ exchanger are elevated or unaltered $(46,47)$. Decreased levels of SERCA reduce $\mathrm{Ca}^{2+}$ diastolic sequestration, leading to an abnormal force-frequency relationship and a decreased developed tension (48). The elevated expression and function of the $\mathrm{Na}^{+} \mathrm{Ca}^{2+}$ exchanger can lead to a large amount of $\mathrm{Na}^{+}$influx, which is further associated with potential membrane depolarization that can generate amplified arrythmogenesis (49). The expression of SR phospholamban protein (a SERCA inhibitor and decreases $\mathrm{Ca}^{2+}$ sequestration) is depressed, representing an adaptive mechanism to compensate for SERCA dysfunction in $\operatorname{HF}(50,51)$.

In cardiac remodelling, both the sympathetic nervous system and the renin-angiotensin system (RAS) are activated, and different studies have demonstrated their relationship with dysfunction of intracellular $\mathrm{Ca}^{2+}$ handling $(52,53)$. ROS also modifies the proteins involved in excitation-contraction coupling, and there is evidence that ROS can suppress L-type $\mathrm{Ca}^{2+}$ channels, causing oxidative interaction with $\mathrm{Ca}^{2+}$ ATPase in the SR to inhibit $\mathrm{Ca}^{2+}$ uptake and enhance the probability of opening ryanodine receptors (54). Accordingly, both oxidative stress and neurohormonal activation can be regarded to play a critical role in the adjustment of $\mathrm{Ca}^{2+}$ handling during the development of cardiac remodelling.

\section{CARDIAC INJURY LEADS TO FIBROSIS}

Cardiac fibroblasts (CFBs) represent a large cell population, corresponding to approximately two-thirds of the cells in the heart. On the other hand, cardiomyocytes constitute approximately two-thirds of the volume of the myocardial tissue (55). Aside from playing a key role in maintaining cardiac geometry, structure, biochemical processes and function, CFBs are essential for optimal electrical conduction in the myocardium $(56,57)$. CFBs play a fundamental role in ECM homeostasis and remodelling. In normal conditions, ECM is composed of fibrillar collagen types I and III, fibronectin, laminin, fibrillin, elastin, glycoproteins and proteoglycans; CFBs are the primary source of these ECM proteins (58). CFBs also produce matrix metalloproteinases (MMPs) as well as tissue inhibitors of MMPs (TIMPs), which are ECM-regulatory proteins. MMPs are proteases that degrade ECM proteins and TIMPs can inhibit MMP function; their balanced equilibrium is critical for ECM homeostasis (59). Fibrosis is a response of hyperactivity of CFBs that proliferates in response to certain stressful stimuli, and recruitment and proliferation of circulating bone marrow-derived cells that infiltrate the myocardium and transform into CFBs (60). It has been reported in some studies that increased levels of collagen synthesis biomarkers (PICP, PINP, PIIINCP, PIIINP) and reduced serum levels of collagen type I degradation biomarker (CITP), result in collagen deposition and fibrosis in cardiac remodelling $(61,62)$.

Transforming growth factor-beta (TGF- $\beta$ ) plays a critical role in fibroblast phenotype modulation and gene expression, inducing interstitial fibrosis (63). TGF- $\beta$ suppresses ECM degradation by inhibiting MMP expression and inducing TIMPs synthesis. In addition, TGF- $\beta$ also induces conversion of different fibroblasts into CFBs, and enhances ECM proteins synthesis $(64,65)$. Several studies have provided evidence indicating a direct link between the RAS and TGF- $\beta$ pathway, suggesting TGF- $\beta$ acts downstream of angiotensin II $(66,67,68)$. ECM remodelling may be the key in cardiac remodelling disease. Impairment of the ECM network structure disorganizes and interrupts myocardial cells and blood vessel connections, leading to a decrease in heart function and destruction of structural integrity. Fibrosis and overproduction of ECM proteins lead to enhanced stiffness of the myocardium wall, systolic and diastolic dysfunction and distorted architecture $(60,62)$.

\section{CONCLUSIONS}

Cardiac remodelling is both an adaptive and maladaptive response to various stressful stimuli. After cardiac stress, many changes at the macroscopic and microscopic level occur, leading to the development of cardiomyocyte hypertrophy, intracellular $\mathrm{Ca}^{2+}$ overload, fibrosis and apoptosis. The major events that result in cardiac remodelling include the production of ROS, neurohormonal activation of the sympathetic nervous system and RAS, and increase in the levels of inflammatory cytokines such as TGF- $\beta$ and TNF- $\alpha$. Despite great progress in this area during more than 40 years of research, cardiac remodelling remains an important topic that warrants more investigation, perhaps because it is the key step in preventing the progress of HF.

AKNOWLEDGEMENTS: The authors thank the International Academy of Cardiovascular Sciences inspiration. Thanks also to the Study Center of Santa Casa of Campo Grande (Brazil), especially to Mrs Neide Mendes for support. They are grateful to Jonathan Pedro for discussions and to Professor Washington and Gisele Cruz for their help in preparing the manuscript. 


\section{REFERENCES}

1. Jugdutt B, ed. In: Aging and Heart Failure. Springer Science + Business Media, New York, 2014:1-475.

2. Cohn JN, Ferrari R, Sharpe N. Cardiac remodeling-concepts and clinical implications: a consensus paper from an international forum on cardiac remodeling. Behalf of an International Forum on Cardiac Remodeling. J Am Coll Cardiol 2000;35:569-82.

3. Hockman JS, Bulkley BH. Expansion of acute myocardial infarction: An experimental study. Circulation 1982;65:1446-50.

4. Pfeffer MA, Braunwald E. Ventricular remodeling after myocardial infarction: Experimental observations and clinical implications. Circulation 1990;81:1161-72.

5. Gaasch WH. Left ventricular radius to wall thickness ratio. Am J Cardiol 1979;43:1189-94.

6. Sayer G, Bhat G. The renin-angiotensin-aldosterone system and heart failure. Cardiol Clin 2014;32:21-32.

7. Florea VG, Cohn JN. The autonomic nervous system and heart failure. Circ Res 2014;114:1815-26.

8. Dhalla NS, Dent MR, Tappia PS, et al. Subcellular remodeling as a viable target for the treatment of congestive heart failure. J Cardiovasc Pharmacol Therapeut 2006;11:31-45.

9. Tan LB, Jalil JE, Pick R, et al. Cardiac myocyte necrosis induced by angiotensin II. Circ Res 1991;69:1185-95.

10. Sharov VG, Sabbah HN, Shimoyama H, et al. Evidence of cardiocyte apoptosis in myocardium of dogs with chronic heart failure. Am J Pathol 1996;148:141-9.

11. Teiger E, Dam TV, Richard L, et al. Apoptosis in pressure overload induced heart hypertrophy in the rat. J Clin Invest 1996;97:2891-7.

12. Olivetti G, Abbi R, Quaini F, et al. Apoptosis in the failing human heart. N Engl J Med 1997;336:1131-41.

13. Villarreal FJ, Kim NN, Ungab GD, et al. Identification of functional angiotensin II receptors on rat cardiac fibroblastos. Circulation 1993;88:2849-61.

14. Weber KT, Pick R, Silver MA, et al. Fibrillar collagen and remodeling of dilated canine left ventricle. Circulation 1990;82:1387-401.

15. Anderson KR, Sutton MG, Lie JT. Histopathological types of cardiac fibrosis in myocardial disease. J Pathol 1978;128:79-85.

16. Braumwald E, Bristow MR. Congestive heart failure: Fifty years of progress. Circulation 2000; 102: IV.14-23.

17. Belch JJ, Bridges AB, Scott N, Chopra M. Oxygen free radicals and congestive heart failure. Br Heart J 1991;65:245-8.

18. Hill MF, Singal PK. Antioxidant and oxidative stress changes during heart failure subsequent to myocardial infarction in rats. Am J Pathol 1996;148:291-300.

19. Tsutsui H, Kinugawa S, Matsushima S. Oxidative stress and heart failure. Am J Physiol Heart Circ Physiol 2011;301:H2181-90.

20. Mann DL. Innate immunity and the failing heart: The cytokine hypothesis revisited. Circ Res 2015;116:1254-68.

21. Ide T, Tsutsui H, Kinugawa S, et al. Mitochondrial electron transport complex I is a potential source of oxygen free radicals in the failing myocardium. Circ Res 1999;85:357-63.

22. Perrelli MG, Pagliaro P, Penna C. Ischemia/reperfusion injury and cardioprotective mechanisms: role of mitochondria and reactive oxygen species. World J Cardiol 2011;3:186-200.

23. Li JM, Shah AM. Mechanism of endothelial cell NADPH oxidase activation by angiotensin II. Role of the p47phox subunit. J Biol Chem 2003;278:12094-100.

24. Bauersachs J, Bouloumie A, Fraccarollo D, et al. Endothelial dysfunction in chronic myocardial infarction despite increased vascular endothelial nitric oxide synthase and soluble guanylate cyclase expression: Role of enhanced vascular superoxide production. Circulation 1999;100:292-8.

25. Heymes C, Bendall JK, Ratajczak P, et al. Increased myocardial NADPH oxidase activity in human heart failure. J Am Coll Cardiol 2003;41:2164-71.

26. Doughan AK, Harrison DG, Dikalov SI. Molecular mechanisms of angiotensin II-mediated mitochondrial dysfunction: linking mitochondrial oxidative damage and vascular endothelial dysfunction. Circ Res 2008;102:488-96.

27. Cappola TP, Kass DA, Nelson GS, et al. Allopurinol improves myocardial efficiency in patients with idiopathic dilated cardiomyopathy. Circulation 2001;104:2407-11.

28. Ukai T, Cheng CP, Tachibana H, et al. Allopurinol enhances the contractile response to dobutamine and exercise in dogs with pacing-induced heart failure. Circulation 2001;103:750-5.
29. Minhas KM, Saraiva RM, Schuleri KH, et al. Xanthine oxidoreductase inhibition causes reverse remodeling in rats with dilated cardiomyopathy. Circ Res 2006;98:271-9.

30. Finkel T. Oxidant signals and oxidative stress. Curr Opin Cell Biol 2003;15:247-254.

31. Kehat I, Molkentin JD. Molecular pathways underlying cardiac remodeling during pathophysiological stimulation. Circulation 2010;122:2727-35.

32. Sabri A, Hughie HH, Lucchesi PA. Regulation of hypertrophic and apoptotic signaling pathways by reactive oxygen species in cardiac myocytes. Antioxid Redox Signal 2003;5:731-40.

33. Bueno OF, De Windt LJ, Tymitz KM, et al. The MEK1-ERK1/2 signaling pathway promotes compensated cardiac hypertrophy in transgenic mice. EMBO J 2000;19:6341-50.

34. Nicol RL, Frey N, Pearson G, et al. Activated MEK5 induces serial assembly of sarcomeres and eccentric cardiac hypertrophy. EMBO J 2001;20:2757-67.

35. Molkentin JD, Lu JR, Antos CL, et al. A calcineurin-dependent transcriptional pathway for cardiac hypertrophy. Cell 1998;93:215-28.

36. Anderson ME. CaMKII and a failing strategy for growth in heart. J Clin Invest 2009;119:1082-5.

37. Zhang T, Maier LS, Dalton ND, et al. The deltaC isoform of CaMKII is activated in cardiac hypertrophy and induces dilated cardiomyopathy and heart failure. Circ Res 2003;92:912-9.

38. Machackova J, Barta J, Dhalla NS. Myofibrillar remodelling in cardiac hypertrophy, heart failure and cardiomyopathies. Can J Cardiol 2006;22:953-68.

39. Harris DE, Work SS, Wright RK, et al. Smooth, cardiac and skeletal muscle myosin force and motion generation assessed by cross-bridge mechanical interactions in vitro. J Muscle Res Cell Motil 1994;15:11-9.

40. Ojamaa K, Petrie JF, Balkman C, et al. Posttranscriptional modification of myosin heavy-chain gene expression in the hypertrophied rat myocardium. Proc Natl Acad Sci USA 1994;91:3468-72.

41. Gidh-Jain M, Huang B, Jain P, et al. Alterations in cardiac gene expression during ventricular remodeling following experimental myocardial infarction. J Mol Cell Cardiol 1998;30:627-37.

42. Mercadier JJ, Bouveret P, Gorza L, et al. Myosin isoenzymes in normal and hypertrophied human ventricular myocardium. Circ Res 1983;53:52-62.

43. Izumo S, Lompre AM, Matsuoka R, et al. Myosin heavy chain messenger RNA and protein isoform transitions during cardiac hypertrophy. Interaction between hemodynamic and thyroid hormone-induced signals. J Clin Invest 1987;79:970-7.

44. Dhalla NS, Wang X, Beamish RE. Intracellular calcium handling in normal and failing hearts. Exp Clin Cardiol 1996;1:7-20.

45. Babick AP, Dhalla NS. Role of subcellular remodeling in cardiac dysfunction due to congestive heart failure. Med Princ Pract 2007;16:81-9.

46. Studer R, Reinecke H, Bilger J, et al. Gene expression of the cardiac $\mathrm{Na}^{+}-\mathrm{Ca}^{2+}$ exchanger in end-stage human heart failure. Circ Res 1994;75:443-53.

47. Hasenfuss G, Schillinger W, Lenhart SE, et al. Relationship between $\mathrm{Na}^{+}-\mathrm{Ca}^{2+}$-exchanger protein levels and diastolic function of failing human myocardium. Circulation 1999;99:641-8.

48. Muliere LA, Hasenfuss G, Leavitt B, et al. Altered myocardial force-frequency relation in human heart failure. Circulation 1992;85:1743-50.

49. Reinecke H, Studer R, Vetter R, et al. Cardiac $\mathrm{Na}^{+} / \mathrm{Ca}^{2+}$ exchange activity in patients with end-stage heart failure. Cardiovasc Res 1996;31:48-54.

50. Shao Q, Ren B, Saini HK, et al. Sarcoplasmic reticulum Ca2+ transport and gene expression in congestive heart failure are modified by imidapril treatment. Am J Physiol Heart Circ Physiol 2005;288:H1674-82.

51. Sasaki T, Inui M, Kimura Y, et al. Molecular mechanism of regulation of $\mathrm{Ca}^{2+}$ pump ATPase by phospholamban in cardiac sarcoplasmic reticulum: Effects of synthetic phospholamban peptides on $\mathrm{Ca}^{2+}$ pump ATPase. J Biol Chem 1992;267:1674-79.

52. Lai L, Raju VS, Delehanty JM, Yatani A, Liang C. Altered sarcoplasmic reticulum $\mathrm{Ca} 2+$ ATPase gene expression in congestive heart failure: Effect of chronic norepinephrine infusion. J Mol Cell Cardiol 1998;30:175-85. 
53. Ju H, Scammell-La FT, Dixon IMC. Altered mRNA abundance of calcium transport genes in cardiac myocytes induced by angiotensin II. J Mol Cell Cardiol 1996;28:1119-28.

54. Zima AV, Blatter LA. Redox regulation of cardiac calcium channels and transporters. Cardiovasc Res 2006;71:310-21.

55. Camelliti P, Borg TK, Kohl P. Structural and functional characterisation of cardiac fibroblasts. Cardiovasc Res 2005;65:40-51.

56. Kohl P. Heterogeneous cell coupling in the heart: An electrophysiological role for fibroblasts. Circ Res 2003;93:381-3.

57. Gaudesius G, Miragoli M, Thomas SP, et al. Coupling of cardiac electrical activity over extended distances by fibroblasts of cardiac origin. Circ Res 2003;93:421-8.

58. Eghbali M. Cardiac fibroblasts: Function, regulation of gene expression, and phenotypic modulation. Basic Res Cardiol 1992;87(Suppl 2):183-9.

59. Moore L, Fan D, Basu R, et al. Tissue inhibitor of metalloproteinases (TIMPs) in heart failure. Heart Fail Rev 2012;17:693-706.

60. Diez J, Querejeta R, Lopez B, et al. Losartan-dependent regression of myocardial fibrosis is associated with reduction of left ventricular chamber stiffness in hypertensive patients. Circulation 2002;105:2512-17.

61. Laviades C, Varo N, Fernandez J, et al. Abnormalities of the extracellular degradation of collagen type I in essential hypertension. Circulation 1998;98:535-40.
62. Fan D, Takawale A, Lee J, et al. Cardiac fibroblasts, fibrosis and extracellular matrix remodeling in heart disease. Fibrogenesis Tissue Repair 2012;5:15.

63. Bujak M, Frangogiannis NG. The role of TGF- $\beta$ signaling in myocardial infarction and cardiac remodeling. Cardiovasc Res 2007;74:184-95.

64. Lijnen PJ, Petrov VV, Fagard RH. Induction of cardiac fibrosis by transforming growth factor-beta(1). Mol Genet Metab 2000;71:418-35.

65. Desmouliere A, Geinoz A, Gabbiani F, et al. Transforming growth factor-beta 1 induces alpha-smooth muscle actin expression in granulation tissue myofibroblasts and in quiescent and growing cultured fibroblasts. J Cell Biol 1993;122:103-11.

66. Rosenkranz S. TGF-beta1 and angiotensin networking in cardiac remodeling. Cardiovasc Res 2004;63:423-32.

67. Sadoshima J, Izumo S. Molecular characterization of angiotensin IIinduced hypertrophy of cardiac myocytes and hyperplasia of cardiac fibroblasts. Critical role of the AT1 receptor subtype. Circ Res 1993; 73:413-23.

68. Gray MO, Long CS, Kalinyak JE, et al. Angiotensin II stimulates cardiac myocyte hypertrophy via paracrine release of TGF-beta 1 and endothelin-1 from fibroblasts. Cardiovasc Res 1998;40:352-63. 